\title{
Acetylcholine-Induced Vasodilation in the Uterine Vascular Bed of Pregnant Rats with Adriamycin-Induced Nephrosis
}

\author{
Mariam H. Yousifa Ayotunde S. Adeagbo ${ }^{b}$ Elizabeth A. Kadavila \\ Bindu Chandrasekhara Mabayoje A. Oriowo ${ }^{a}$ \\ aDepartment of Pharmacology and Toxicology, Faculty of Medicine, Kuwait University, Kuwait; \\ bDepartment of Physiology and Biophysics, University of Louisville, Ky., USA
}

\author{
Key Words \\ Preeclampsia · Adriamycin · Nephrosis . \\ Endothelium-dependent vasodilation
}

\begin{abstract}
Objective: This project was designed to study endothelium-dependent vasodilation in the uterine vascular bed during experimentally induced preeclampsia in rats. Methods: Uterine vascular beds were isolated from nonpregnant and pregnant rats with or without treatment with adriamycin (ADR) and perfused with physiological solution. Thereafter, vasodilator responses to acetylcholine were recorded. Records: Pregnant ADR-treated rats displayed symptoms of preeclampsia including hypertension and proteinuria. Blood pressure was $110.0 \pm$ $4.7 \mathrm{~mm} \mathrm{Hg}(n=5)$ in control pregnant rats and $136.0 \pm$ $5.3 \mathrm{~mm} \mathrm{Hg}(\mathrm{n}=5)$ in ADR-treated pregnant rats, and urinary protein concentrations were $0.35 \mathrm{mg} / \mathrm{ml}(\mathrm{n}=5)$ and $13.2 \pm 3.6 \mathrm{mg} / \mathrm{ml}(\mathrm{n}=9)$, respectively. Both blood pressure and proteinuria values were significantly $(p<0.05)$ different between controls and ADR-treated rats. However, acetylcholine-induced dose-dependent vasodilator responses in the vascular beds were not significantly different between the pregnant and nonpregnant rats. Although acetylcholine-induced vasodilation was significantly reduced by $\mathrm{N} \omega$-nitro-L-arginine methyl ester hydrochloride (L-NAME) in both groups, the residual re-
\end{abstract}

sponse to acetylcholine was not affected by indomethacin, suggesting that prostanoids were not involved in this response. The L-NAME-resistant component, endothelium-derived hyperpolarizing factor (EDHF), was greater in ADR-treated uterine beds than in those of the controls, indicating a significant contribution from EDHF in these vessels. In the presence of an elevated external potassium ion concentration, acetylcholine produced similar vasodilator responses, indicating that the release of nitric oxide was not impaired. Conclusion: These results indicate that endothelium-dependent vasodilation was not impaired in this model of preeclampsia.

Copyright $($ 2002S. Karger AG, Base

\section{Introduction}

Preeclampsia, which is characterized by increased peripheral vascular resistance, proteinuria and hypertension, has long been a major cause of maternal death and perinatal morbidity. A number of theories have been propounded to explain the hemodynamic features of preeclampsia. One of the theories involves nitric oxide (NO). $\mathrm{NO}$ is a labile gas produced from arginine through a process catalyzed by the enzyme NO synthase (NOS). In blood vessels (and other tissues as well), NO activates guanylate cyclase, increases the intracellular concentration of cyclic guanosine monophosphate and produces vasodila-

\begin{tabular}{ll}
\hline KARGER & ( ) 2002 S. Karger AG, Basel \\
Fax +4161306 1234 & 1011-7571/02/0112-0057\$18.50/0 \\
$\begin{array}{l}\text { E-Mail karger@karger.ch } \\
\text { www.karger.com }\end{array}$ & $\begin{array}{l}\text { Accessible online at: } \\
\text { www.karger.com/journals/mpp }\end{array}$
\end{tabular}

Mabayoje A. Oriowo

Department of Pharmacology and Toxicology

Faculty of Medicine, Kuwait University

PO Box 24923, Safat 13110 (Kuwait)

Tel. +965 5312300 (ext 6327), Fax +965 5342583, E-Mail Oriowo@hsc.kuniv.edu.kw 
tion. In normal pregnancy, there is a significant increase in uteroplacental blood flow and cardiac output associated with a reduced uterine and systemic vascular resistance. This reduction in peripheral vascular resistance is attributed to an increase in the release of NO from the endothelium. This idea was based on a number of observations, including increased expression and activity of endothelial NOS [1] and increased basal NO production during pregnancy [2-6]. In addition, many studies have documented increased endothelium-dependent relaxation in arterial smooth muscles during pregnancy [4, 610]. However, controversy surrounds the status of NO in preeclampsia. Direct measurement of plasma or urinary excretion of nitrite/nitrate has yielded conflicting results. Some workers [11] have reported a decrease in urinary levels of NO in individuals with preeclampsia, while others have reported either no change or an increase in NO levels [12-14]. Inability to control the dietary intake of nitrates could be responsible for these conflicting results. However, Conrad et al. [13] did not observe any change in plasma and urinary nitrite levels in normotensive and preeclamptic women on a reduced nitrite diet. Studies in animal models of preeclampsia have also not been conclusive. In pregnant rats with nephrosis [induced by adriamycin (ADR) injection], Podjarny et al. [15] observed a reduction in the urinary excretion of nitrite/nitrate. However, in another model of preeclampsia, the reduced uterine perfusion pressure model, Alexander et al. [16] did not observe any change in urinary nitrite/nitrate levels even though blood pressure was increased by up to $20 \mathrm{~mm} \mathrm{Hg}$. Since these animals were maintained on standard laboratory rat chow, it is unlikely that the conflicting results (with respect to nitrite levels) could be due to differences in dietary protein intake.

Most investigations on endothelial function in preeclampsia have been carried out using fetal vessels or even vessels not directly related to the reproductive system such as the aorta, mesenteric vascular bed and omental artery segments. During pregnancy, the greatest changes in blood flow take place in the uterine vessels of the maternal circulation. Therefore, it is essential that studies on vascular reactivity be carried out on these vessels. Not many studies in humans or experimental animals have been carried out using vessels from the maternal circulation. Our objective in this investigation was therefore to study endothelium-dependent vasodilation in the perfused uterine vascular bed in pregnant rats with nephrosis induced by ADR. This animal model displays some of the signs and symptoms of preeclampsia [15].

\section{Materials and Methods}

\section{Animals and Tissue Preparation}

Adult female Sprague-Dawley rats weighing 180-250 g were used in this study. The rats were bred and maintained under internationally accepted conditions in the Animal Resource Center of the Faculty of Medicine, Kuwait University. Each rat was killed by concussion followed by exsanguination. The common iliac artery was identified and traced up to the point where it branches into the internal and external iliac arteries. Ligatures were placed around these branches and tied securely. The common iliac artery was then cut at its point of origin from the abdominal aorta and isolated en bloc with the uterine horn attached. The whole preparation was placed in a humidified chamber for perfusion. The preparation was perfused through a cannula placed in the iliac artery with Krebs' solution $\left(37^{\circ} \mathrm{C}\right)$ at a constant flow rate of $6 \mathrm{ml} / \mathrm{min}$ using a Masterflex peristaltic pump (ColePalmer). Perfusion pressure was recorded through a Lectromed SensorNor 80 connected to a 2-channel Lectromed polygraph recorder. The preparation was allowed to stabilize for $30 \mathrm{~min}$, at the end of which a dose of noradrenaline $(100 \mathrm{nmol})$ was administered to test for tissue responsiveness. Thereafter, the preparation was allowed to equilibrate for another $30 \mathrm{~min}$ before starting the experiment.

\section{Vasodilator Responses}

When vasodilator responses were to be obtained, phenylephrine $\left(10^{-5} \mathrm{M}\right)$ was added to the physiological solution perfusing the tissue. Once the perfusion pressure had stabilized at the new level, increasing doses of acetylcholine were administered as above to generate data for a dose-response curve. Vasodilator responses were expressed as the percentage reduction in phenylephrine-induced tone.

\section{Treatment with ADR}

Adult female Sprague-Dawley rats weighing 180-250 g were used for our experiments. The rats were divided into four groups: (1) nonpregnant rats; (2) nonpregnant ADR-treated rats; (3) pregnant rats, and (4) pregnant ADR-treated rats. ADR-treated rats received a single injection of ADR, $7.5 \mathrm{mg} / \mathrm{kg}$, through the tail vein. Two weeks later, a group of ADR-treated and matching nontreated rats were mated with fertile males for up to 4 days. The day spermatozoa appeared in the vaginal smear was designated as day 1 of pregnancy. Animals were sacrificed on day 20 of pregnancy for in vitro uterine vascular bed perfusion experiments.

\section{Blood Pressure and Urinary Protein Measurements}

Blood pressure was measured before the animals were sacrificed. To measure blood pressure, rats were anesthetized with sodium pentobarbitone, $40 \mathrm{mg} / \mathrm{kg}$, administered intraperitoneally. Thereafter, an incision was made in the neck region and the right common carotid artery was exposed and isolated. The artery was cannulated with a PE50 polyethylene cannula connected to a blood pressure transducer (SensorNor 80), and blood pressure was recorded on a 2-channel Lectromed physiological recorder. The concentration of proteins in the urine was measured colorimetrically using the Bio-Rad protein assay kit.

\section{Measurement of Plasma Concentration of Nitrite}

The plasma concentration of nitrite was measured using a nitrate/nitrite colorimetric assay kit (Assay Designs) following enzymatic conversion of nitrate into nitrite. The nitrite was detected colorimetrically (at 540-nm visible light) as a colored product of the Griess reaction. 


\section{Physiological Solution}

The physiological solution used throughout this study was of the following composition (in mmol/l): $\mathrm{NaCl} 119, \mathrm{KCl} 4.7, \mathrm{MgCl}_{2} 1.2$, $\mathrm{KH}_{2} \mathrm{PO}_{4} 1.2, \mathrm{CaCl}_{2} 2.5, \mathrm{NaHCO}_{3} 25$ and glucose 11.0. The $\mathrm{pH}$ was approximately 7.4. The solution was gassed continuously with a $5 \%$ $\mathrm{CO}_{2}-95 \% \mathrm{O}_{2}$ mixture.

\section{Data Analysis}

Graphs were plotted and analyzed using the GraphPad Prism software. $\mathrm{EC}_{50}$ (agonist concentration producing $50 \%$ of the maximum response) values were obtained from a plot of response against molar concentration of the agonist. Agonist potencies were expressed as $\mathrm{pD}_{2}\left(-\log \mathrm{EC}_{50}\right)$ values. Data were presented as mean $\pm \mathrm{SE}$ of ' $\mathrm{n}$ ' number of animals used in the experiments. Differences between mean values were compared using Student's t test. The difference was considered to be significant when $\mathrm{p}<0.05$.

\section{Drug Solutions}

The following compounds were used in this investigation: phenylephrine hydrochloride, ADR (doxorubicin hydrochloride, adriablastina), isoprenaline bitartrate, N $\omega$-nitro- $L$-arginine methyl ester hydrochloride (L-NAME), sodium nitroprusside, iso-octylphenoxypolyethoxyethanol (Triton X-100), indomethacin and acetylcholine hydrochloride. Indomethacin was dissolved in absolute ethanol while all other compounds were dissolved in water. With the exception of ADR (supplied by the Ministry of Health, Kuwait) and Triton X-100 (from BDH Laboratories), all other compounds were obtained from RBI (Natick, Mass., USA).

\section{Results}

\section{Effects of ADR Treatment}

Pregnant ADR-treated rats developed proteinuria and hypertension, which were absent in control pregnant rats. Blood pressure was $115.8 \pm 4.7 \mathrm{~mm} \mathrm{Hg}$ in control nonpregnant rats, while the values in control and ADRtreated pregnant rats were $110.0 \pm 4.7 \mathrm{~mm} \mathrm{Hg}(\mathrm{n}=5)$ and $136.0 \pm 5.3 \mathrm{~mm} \mathrm{Hg}(\mathrm{n}=5)$, respectively. Thus, blood pressure was significantly $(\mathrm{p}<0.05)$ higher in ADRtreated pregnant rats compared with control pregnant rats. Since previous studies have established that ADR treatment alone has no effect on blood pressure [15], we did not routinely measure blood pressure in ADR-treated nonpregnant rats in this study. Urinary protein concentrations in the four groups of animals are shown in table 1. The urinary protein concentration was very low in untreated pregnant and nonpregnant rats, and there was no significant difference $(p>0.05)$ between urinary protein concentrations in these groups. However, treatment of rats with ADR resulted in a significant $(\mathrm{p}<0.05)$, approximately 10 -fold increase in urinary protein concentration which increased further during pregnancy.

In pregnant control rats, the level of nitrite/nitrate in the plasma was $105 \pm 14.3 \mu \mathrm{mol} / \mathrm{l}(\mathrm{n}=8)$, which was
Table 1. Urinary protein concentrations in pregnant and nonpregnant ADR-treated and untreated rats

Animal group Protein concentration $\mathrm{mg} / \mathrm{ml}$

Nonpregnant rats (group 1)

$0.35 \pm 0.05(\mathrm{n}=4)$

Nonpregnant, ADR-treated rats (group 2)

Pregnant rats (group 3)

Pregnant, ADR-treated rats (group 4)

$3.73 \pm 0.51^{1}(\mathrm{n}=10)$

$0.35 \pm 0.09^{2}(\mathrm{n}=5)$

$13.2 \pm 3.6^{2}(\mathrm{n}=9)$

(versus group 1$)$

$\mathrm{p}<0.05$ (versus groups 2 and 3 ).

significantly $(\mathrm{p}<0.05)$ higher than that in ADR-treated pregnant rats $(61.8 \pm 3.9 \mu \mathrm{mol} / 1 ; \mathrm{n}=10)$.

\section{Vasodilator Effect of Acetylcholine in the Perfused Rat}

\section{Uterine Vascular Bed}

In all uterine vascular bed preparations, the basal perfusion pressure remained steady throughout the duration of the experiments. In phenylephrine-constricted uterine vascular beds, acetylcholine $\left(10^{-11}-10^{-6} \mathrm{~mol}\right)$ produced dose-dependent vasodilator responses. Some preparations (about 50\%) from nonpregnant rats did not respond to acetylcholine even when the same preparations responded with vasodilation to isoprenaline. However, acetylcholine produced reproducible vasodilator responses in all preparations from pregnant rats. As shown in figure 1, acetylcholine-induced vasodilation was significantly greater in preparations from pregnant rats. Perfusion of the vascular bed with Triton X-100 to remove the endothelium resulted in the loss of acetylcholine-induced vasodilation, indicating the dependence of the acetylcholineinduced response on the endothelium. Therefore, in this study, acetylcholine-induced vasodilation was used to assess endothelial function.

Acetylcholine $\left(10^{-11}-10^{-6} \mathrm{~mol}\right)$ produced weak but dose-dependent vasodilator responses in uterine vascular beds from nonpregnant rats treated with ADR (fig. 1). Only 2 out of 5 preparations tested responded to acetylcholine. However, acetylcholine in the same dose range produced significant dose-dependent vasodilator responses in all vascular beds from control (not treated with ADR) and ADR-treated pregnant rats (fig. 1). The potency of acetylcholine was not significantly $(p>0.05)$ different between the two groups. The $\mathrm{pD}_{2}$ values were $9.06 \pm$ 0.22 (control pregnant rats, $\mathrm{n}=5$ ) and $9.09 \pm 0.19$ (ADRtreated pregnant rats, $\mathrm{n}=5$ ). The maximum dilator 
Fig. 1. Vasodilator effects of acetylcholine in perfused uterine vascular beds isolated from nonpregnant $(\boldsymbol{\square} ; \mathrm{n}=9)$, pregnant $(\mathbf{\Delta} ; \mathrm{n}=5)$ and ADR-treated pregnant $(\boldsymbol{\nabla} ; \mathrm{n}=7)$ and nonpregnant $(\triangle ; \mathrm{n}=5)$ rats. Perfusion pressure was raised with an infusion of phenylephrine $\left(10^{-5} \mathrm{M}\right)$.
Fig. 2. L-NAME $\left(10^{-4} M\right)$-resistant acetylcholine-induced vasodilation in perfused uterine vascular beds from control $(\boldsymbol{\square} ; n=5)$ and ADR-treated $(\boldsymbol{\Delta} ; \mathrm{n}=5)$ pregnant rats. Perfusion pressure was raised with an infusion of phenylephrine $\left(10^{-5} M\right)$.
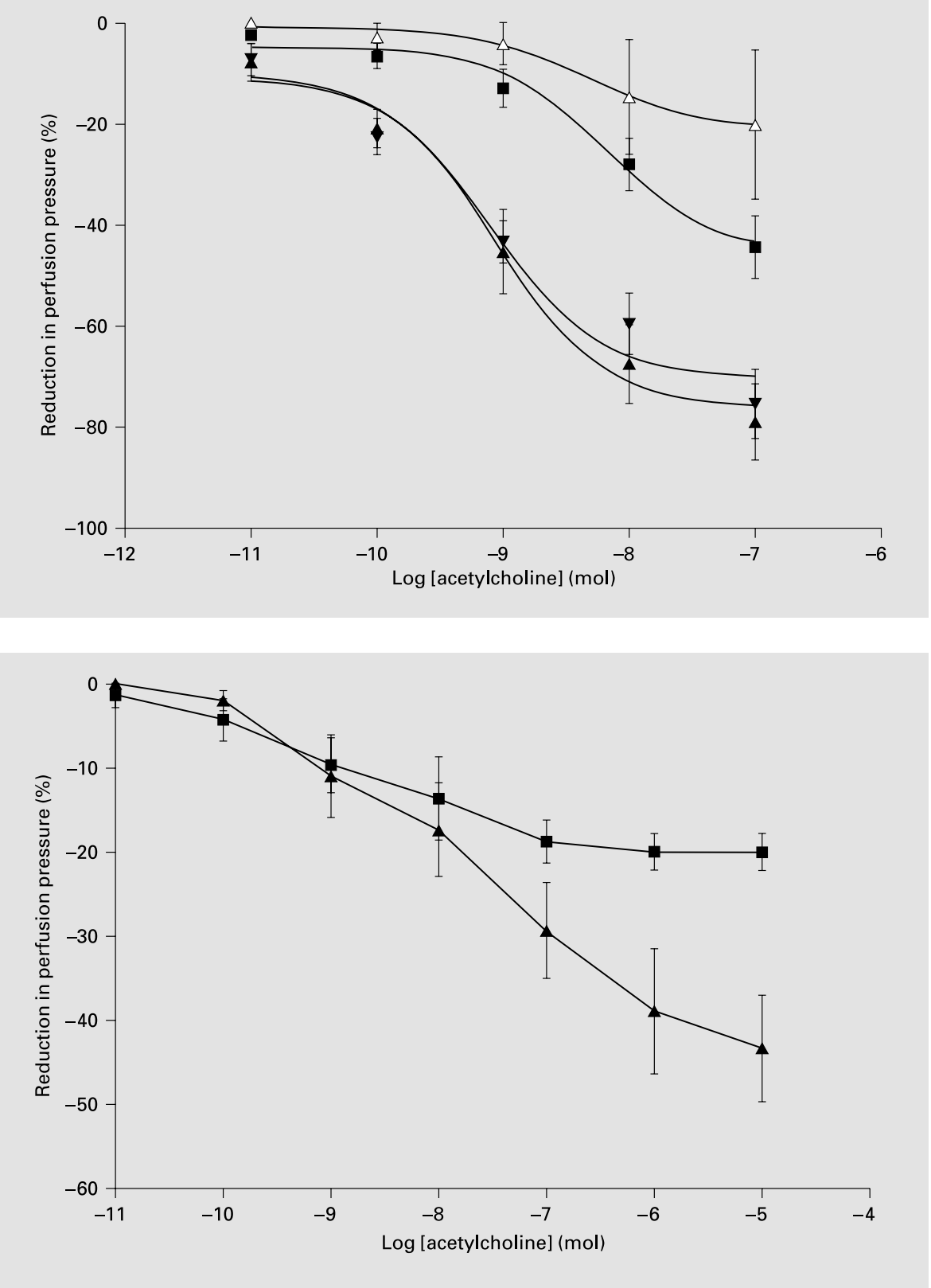

response in ADR-treated rats $(70.3 \pm 4.3 \%)$ was slightly but not significantly $(p>0.05)$ less than the value in control (not treated with ADR) rats $(76.2 \pm 5.3 \%)$.

\section{Effect of L-NAME on Acetylcholine-Induced}

Vasodilation in Control and ADR-Treated Pregnant

Rats

L-NAME $\left(10^{-4} M\right)$ did not enhance phenylephrineinduced vasoconstriction in control or ADR-treated pregnant rats. However, L-NAME $\left(10^{-4} M\right)$ significantly re- duced, but did not abolish, acetylcholine-induced vasodilation in both groups. The residual response to acetylcholine was significantly higher in uterine vascular beds isolated from ADR-treated pregnant rats when compared with preparations from control pregnant rats (fig. 2). The $\mathrm{pD}_{2}$ values were $8.69 \pm 0.35$ (control pregnant rats, $\mathrm{n}=5$ ) and $7.66 \pm 0.29$ (ADR-treated pregnant rats, $n=5$ ), while the maximum residual dilator responses in the presence of L-NAME were $18.9 \pm 1.6$ and $40.0 \pm 3.5 \%$, respectively. The residual responses were not affected by indo- 
Fig. 3. Acetylcholine-induced vasodilation in uterine vascular beds from $\operatorname{control}(\boldsymbol{\square} ; \mathrm{n}=$ 4) and ADR-treated $(\mathbf{\Delta} ; n=4)$ pregnant rats in the presence of an elevated $\mathrm{KCl}(40 \mathrm{mM})$ concentration in the physiological solution. Perfusion pressure was raised with an infusion of phenylephrine $\left(10^{-5} \mathrm{M}\right)$
Fig. 4. Vasodilator effects of sodium nitroprusside in perfused uterine vascular beds isolated from control $(\mathbf{\square} ; \mathrm{n}=4)$ and ADRtreated $(\mathbf{\Delta} ; \mathrm{n}=6)$ pregnant rats. Perfusion pressure was raised with an infusion of phenylephrine $\left(10^{-5} \mathrm{M}\right)$.
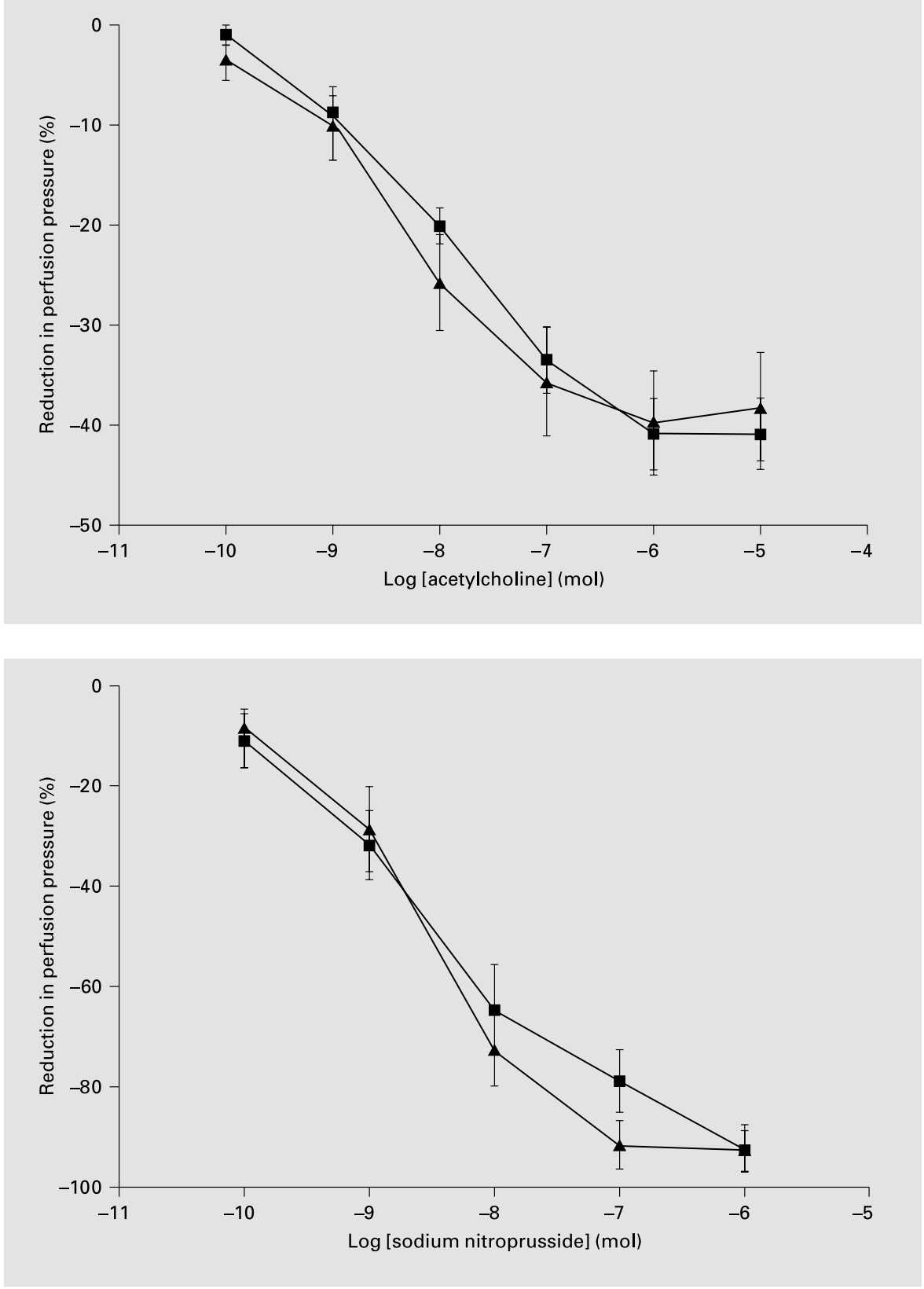

methacin $\left(10^{-5} M\right)$ in either group, indicating that the residual response did not involve prostanoids. However, the residual responses were abolished in a high- $\mathrm{K}^{+}$ (40 $\mathrm{mM}$ ) medium, suggesting a role for membrane hyperpolarization.

In an attempt to determine if the higher L-NAMEresistant component of acetylcholine-induced vasodilation in ADR-treated rats was due to reduced release of NO, we examined acetylcholine-induced vasodilation under conditions in which the external $\mathrm{K}^{+}$in the physiologi- cal solution was increased from 4.7 to $40 \mathrm{~m} M$. Briefly, the $\mathrm{K}^{+}$concentration in the physiological solution was increased to $40 \mathrm{~m} M$, and perfusion pressure was raised with phenylephrine as described above. After the perfusion pressure had stabilized, doses of acetylcholine were injected as above. The results are shown in figure 3. Acetylcholine produced potent vasodilation of the uterine vascular beds from both control and ADR-treated pregnant rats. There was no significant difference $(p>0.05)$ in either potency (control $8.3 \pm 0.3$ versus ADR $7.9 \pm 0.2$ ) or 
maximum response to acetylcholine (control $40.2 \pm 1.8 \%$ versus ADR $38.9 \pm 2.8 \%$ ).

\section{Vasodilator Effect of Sodium Nitroprusside in the Perfused Rat Uterine Vascular Bed}

This series of experiments was performed in order to determine if there was a change in the sensitivity of the uterine vascular bed to NO. Sodium nitroprusside $\left(10^{-10}\right.$ $10^{-6} \mathrm{~mol}$ ) produced dose-dependent vasodilation in uterine vascular beds from control and ADR-treated pregnant rats (fig. 4). Sodium nitroprusside-induced vasodilation was not significantly $(\mathrm{p}>0.05)$ different between the two groups. The $\mathrm{pD}_{2}$ values were $9.06 \pm 0.22$ (control rats, $\mathrm{n}=5$ ) and $9.09 \pm 0.19$ (ADR-treated rats, $\mathrm{n}=5$ ), while maximum dilator responses were $76.2 \pm 5.3$ and $70.3 \pm$ $4.3 \%$, respectively.

\section{Discussion}

Rats that became pregnant 2 weeks after treatment with a single intravenous dose of ADR developed symptoms of preeclampsia, including hypertension, proteinuria and reduced glomerular filtration [15]. The symptoms are reversible, as they disappear immediately after parturition, indicating that they were pregnancy related. There was a significant reduction in the urinary excretion of nitrite/nitrate in pregnant ADR-treated rats. The observation that L-NAME, an NOS inhibitor, increased blood pressure in control but not ADR-treated pregnant rats appears to confirm that the elevated blood pressure observed in this model was linked to inadequate release of NO [15]. ADR-induced hypertension in pregnant rats is therefore a good model for studying the pathophysiology of preeclampsia. Results obtained in our studies have confirmed these observations. In our study, blood pressure increased from $110 \mathrm{~mm} \mathrm{Hg}$ in control pregnant rats to $136 \mathrm{~mm} \mathrm{Hg}$ in ADR-treated pregnant rats. Also, the urinary protein concentration was $0.35 \mathrm{mg} / \mathrm{ml}$ in control pregnant rats, while in ADR-treated pregnant rats, it was $13.6 \mathrm{mg} / \mathrm{ml}$. In addition, the plasma level of nitrite/nitrate in ADR-treated pregnant rats was approximately $50 \%$ of that found in control pregnant rats. We therefore used this animal model of preeclampsia to study endotheliumdependent vasodilator responses to acetylcholine during the development of preeclampsia.

Our results showed that endothelium-dependent acetylcholine-induced vasodilation was increased in vascular beds isolated from pregnant rats compared with those from nonpregnant controls. This is consistent with pre- vious reports in the literature [4,6-10]. The fact that acetylcholine-induced vasodilation was significantly inhibited by L-NAME would argue in favor of a role for NO in the response to acetylcholine.

The effect of preeclampsia on endothelium-dependent relaxation is still unresolved. Most functional studies in vitro have shown that agonist-induced relaxation (index of NO release) was significantly reduced in vessels obtained from women with pregnancy-induced hypertension [10, 17-20]. A similar observation has been made in an animal model of preeclampsia [21]. However, Rathaus et al. [22], using ADR-treated pregnant rats as a model of preeclampsia, reported increased acetylcholine-induced, endothelium-dependent relaxation of the mesenteric vessels, indicating an increased release of NO. None of these studies was carried out using resistance vessels of the maternal circulation.

ADR-induced preeclampsia-like syndrome is associated with a reduced basal plasma nitrite/nitrate level indicating endothelial dysfunction as previously reported [15] and consistent with the results of the present study. We therefore used this model to study endothelium-dependent vasodilation in the uterine vascular bed during the development of preeclampsia. Our results showed that acetylcholine produced reproductive vasodilator responses in uterine vascular beds from control and preeclamptic (ADR-treated) pregnant rats. There was no significant difference either in the potency of acetylcholine or in the maximum dilator response indicating lack of endothelial dysfunction in this animal model of preeclampsia.

It is known that acetylcholine-induced vasodilation, especially in resistance vessels, is made up of two components, i.e. NO and endothelium-derived hyperpolarizing factor (EDHF) components [23, 24]. The contribution of NO and EDHF to agonist-induced vasodilation varies between vascular beds. There is the possibility that a reduction in one component could be compensated for by an increase in the other component. We therefore studied the effect of L-NAME, an inhibitor of NOS activity, on acetylcholine-induced vasodilation in uterine vascular beds from control and ADR-treated pregnant rats. The results showed that L-NAME produced significant inhibition of acetylcholine-induced vasodilation in both groups. In addition, L-NAME did not totally abolish acetylcholine-induced vasodilation, thereby leaving a residual vasodilator response. This residual L-NAME-insensitive component (EDHF) was resistant to inhibition by indomethacin, a cyclooxygenase inhibitor, indicating that the response was not mediated by prostanoids. The residual 
response was, however, abolished by increasing the $\mathrm{K}^{+}$ content of the physiological solution, suggesting a role for membrane hyperpolarization in this response. Perhaps more significant was our observation that the presumed EDHF component was significantly greater in uterine vascular beds isolated from ADR-treated pregnant rats compared with those from the control pregnant rats. This could be due to one of three possibilities: (1) NO release is impaired by adriamycin treatment; (2) the sensitivity of the uterine vascular bed to NO is reduced during preeclampsia, or (3) the release of EDHF is increased during preeclampsia. In order to determine whether NO release is impaired in ADR-treated pregnant rats, we attempted to isolate the $\mathrm{NO}$ component of the relaxation response to acetylcholine. In the rat mesenteric vascular bed, acetylcholine-induced vasodilation, though endothelium dependent, was not abolished by L-NAME, an NOS inhibitor [23]. These investigators, however, showed that depolarization of the vascular preparation by elevating the external $\mathrm{K}^{+}$concentration to $20 \mathrm{~m} M$ reduced acetylcholine-induced vasodilation. In addition, and perhaps more significantly, under this condition, the vasodilator response to acetylcholine was abolished by L-NAME, indicating total dependence of this response on NO release. We have previously, in two preliminary experiments, stated that in the perfused rat uterine vascular bed, acetylcholine-induced vasodilation in the presence of $40 \mathrm{mM}$ $\mathrm{K}^{+}$was abolished by L-NAME $\left(10^{-4} M\right)$. This would indicate that the response was mediated primarily by NO. We therefore adopted this procedure, in this study, to compare the NO component of the acetylcholine-induced response in uterine vascular beds from ADR-treated and untreated pregnant rats. The results showed that in the presence of $40 \mathrm{mM} \mathrm{K} \mathrm{K}^{+}$in the perfusion solution and phenylephrine to raise perfusion pressure, acetylcholine produced vasodilator responses in both ADR-treated and untreated rat uterine vascular beds. There was no significant difference in the response (either potency or maximum response) to acetylcholine between the two groups. This would suggest that acetylcholine-induced release of NO was not impaired in this model of preeclampsia. Thus, even though reduction of plasma levels of nitrite/ nitrate by ADR treatment was observed in this study, as previously reported [15], acetylcholine-induced release was not reduced, indicating a dissociation between basal and induced release of $\mathrm{NO}$ in this model of preeclampsia. This dissociation was also observed by Rathaus et al. [22], who noted an increased acetylcholine-induced vasodilation in the mesenteric bed of pregnant rats with nephrosis (induced by ADR). Similarly, Crews et al. [21] reported reduced endothelium-dependent relaxation in the aorta of rats with preeclampsia-like syndrome, in a reduced uterine perfusion pressure model, even though no change in urinary excretion of nitrite/nitrate was observed when compared with control pregnant rats [16].

We did not observe any difference in the reactivity of the uterine vascular beds (treated with ADR or not) to sodium nitroprusside, an NO donor, suggesting that the sensitivity of the uterine vascular bed to NO was not impaired by treatment with ADR.

\section{Conclusion}

We interpreted these observations to indicate (1) that induced release of NO in the rat uterine vascular bed was not altered by preeclampsia, (2) that both NO and EDHF were involved in acetylcholine-induced vasodilation in control and ADR-treated pregnant rats and (3) that the increased L-NAME-resistant component of acetylcholineinduced vasodilation in ADR-treated pregnant rats was not due to impaired NO release.

\section{Acknowledgement}

This study was supported by a grant (KFAS-98-07-01) from the Kuwait Foundation for the Advancement of Sciences. 


\section{References}

1 Sladek SM, Magness RR, Conrad KP: Nitric oxide and pregnancy. Am J Physiol 1997;272: R441-R463.

2 Conrad KP, Joffe GM, Kruszyna H, Kruszyna R, Rochelle LG, Smith RP, Chavez JE, Mosher MD: Identification of increased nitric oxide biosynthesis during pregnancy in rats. FASEB J 1993; 7:566-571.

3 Weiner C, Liu KZ, Thompson L, Herrig J, Chestnut D: Effect of pregnancy on endothelium and smooth muscle: Their role in reduced adrenergic sensitivity. Am J Physiol 1991;261: H1275-H1283.

4 Nelson SH, Steinsland OS, Suresh MS, Lee NM: Pregnancy augments nitric oxide-dependent dilator response to acetylcholine in the human uterine artery. Hum Reprod 1998;13: 1361-1367.

5 Li P, Tong C, Eisenach JC: Pregnancy and ephedrine increase the release of nitric oxide in ovine uterine arteries. Anesth Analg 1996;82: 288-293.

6 Ni Y, Meyer M, Osol G: Gestation increases nitric oxide-mediated vasodilation in rat uterine arteries. Am J Obstet Gynecol 1997;176: 856-864.

7 Williams DJ, Vallance PJ, Neild GH, Spencer JA, Imms FJ: Nitric oxide-mediated vasodilation in human pregnancy. Am J Physiol 1997; 272:H748-H752.

8 Weiner C, Martinez E, Zhu LK, Ghodsi A, Chestnut D: In vitro release of endotheliumderived relaxing factor by acetylcholine is increased during the guinea pig pregnancy. Am J Obstet Gynecol 1989;161:1599-1605.

9 Gerber RT, Anwar MA, Poston L: Enhanced acetylcholine induced relaxation in small mesenteric arteries from pregnant rats: An important role for endothelium-derived hyperpolarizing factor (EDHF). Br J Pharmacol 1998;125: $455-460$.
10 Knock GA, Poston L: Bradykinin-mediated relaxation of isolated maternal resistance arteries in normal pregnancy and preeclampsia. Am J Obstet Gynecol 1996;175:1668-1674.

11 Davidge ST, Stranko CP, Roberts JM: Urine but not plasma nitric oxide metabolites are decreased in women with preeclampsia. Am J Obstet Gynecol 1996;174:1008-1013.

12 Di Iorio R, Marinoni E, Emiliani S, Villacio B, Cosmi EV: Nitric oxide in preeclampsia: Lack of evidence for decreased production. Eur $\mathbf{J}$ Obstet Gynecol Reprod Biol 1998;76:65-70.

13 Conrad KP, Kerchner LJ, Mosher MD: Plasma and 24-h $\mathrm{NO}(\mathrm{x})$ and cGMP during normal pregnancy and preeclampsia in women on a reduced NO(x) diet. Am J Physiol 1999;277: F48-F57.

14 Ranta V, Viinikka L, Halmesmaki E, Ylikorkala O: Nitric oxide production with preeclampsia. Obstet Gynecol 1999;93:442-445.

15 Podjarny E, Ben-Chetrit S, Rathaus M, Korzets Z, Green J, Katz B, Bernheim J: Pregnancyinduced hypertension in rats with adriamycin nephropathy is associated with an inadequate production of nitric oxide. Hypertension 1997; 29:986-991.

16 Alexander BT, Kassab SE, Miller MT, Abram SR, Reekelhoff JF, Bennet WA, Granger JP: Reduced uterine perfusion pressure in the rat is associated with increases in arterial pressure and changes in renal nitric oxide. Hypertension 2001;37:1191-1195
17 Pinto A, Sorrentino R, Sorrentino P, Guerritore T, Miranda L, Biondi A, Martinelli P. Endothelial-derived relaxing factor released by endothelial cells of human umbilical vessels and its impairment in pregnancy-induced hypertension. Am J Obstet Gynecol 1991;164: 507-513.

18 McCarthy AL, Woolfson RG, Raju SK, Poston $\mathrm{L}$ : Abnormal endothelial cell function of resistance arteries from women with preeclampsia Am J Obstet Gynecol 1993;168:1323-1330.

19 Akar F, Ark M, Uydes BS, Soysal ME, Saracoglu F, Abacioglu N, van de Voorde J, Kanzik I: Nitric oxide production by human umbilical vessels in severe pre-eclampsia. J Hypertens 1994; 12:1235-1241.

20 Ashworth JR, Baker PN, Warren AY, Johnson IR: Mechanisms of endothelium-dependent relaxation in myometrial resistance vessels and their alteration in preeclampsia. Hypertens Pregnancy 1999;18:57-71.

21 Crews JK, Herrington JN, Granger JP, Khali RA: Decreased endothelium-dependent vascular relaxation during reduction of uterine perfusion pressure in pregnant rats. Hypertension 2000;35:367-372.

22 Rathaus M, Podjarny E, Benchetrit S, Green J, Bernheim J: Nitric oxide and vascular reactivity in pregnant rats with adriamycin nephropathy. Clin Sci (Lond) 1997;93:227-234.

23 Garland JG, McPherson GA: Evidence that nitric oxide does not mediate the hyperpolarization and relaxation to acetylcholine in the rat small mesenteric artery. Br J Pharmacol 1992; 105:429-435.

24 Adeagbo ASO, Triggle CR: Varying extracellular $[\mathrm{K}+]$ : A functional approach to separating EDHF- and EDNO-related mechanisms in perfused rat mesenteric arterial bed. J Cardiovasc Pharmacol 1993;21:423-429. 